cardiac measurements, which are vitually irrelevant to the case they are making. Thirdly, from table III it seems that no patient received more than three injections of morphine. As this was over several months I wonder at the need for an implantable system, with all the associated risks of contamination and infection. Intermittent injection might have been just as effective.

Unfortunately this interesting, but anecdotal, account of the use of a new idea does not really help me in trying to treat patients with chronic anginal pain, as I cannot assess the value of the technique from the data provided.

W G NoTcUTT

James Paget Hospital,

Great Yarmouth NR31 6LA

AUTHORS' REPLY -All of the patients in our group had been receiving intramuscular opiates once or more daily in doses that caused unacceptable side effects. Dr W G Notcutt's confusion about the extent of pain relief is understandable, and our use of the word "lessened" was incorrect. We would like to emphasise that all of the patients were free of anginal pain while receiving daily treatment with epidural opiates.

Though anginal pain is not always caused by ischaemia, we believe that our cardiological data are relevant as they illustrate the haemodynamic and angiographic state of our patients, whose cardiac condition was such that they experienced several attacks of angina daily. With regard to $\mathrm{Dr}$ Notcutt's last point, we would like to point out that the numbers of injections of morphine in table III were daily totals.

Before treatment our patients were severely incapacitated, but they have now resumed their previous physical activities.

Søren Eigil Clemensen Per Thayssen Peter Holebma

Odense University Hospital,

DK-5000 Odense C,

Denmark

\section{The Liverpool urban obstetric flying squad}

SIR,-We would like to reply to some of the points raised by Dr G P R Browne, Dr C C Callander, and Drs A D G Roberts and C A J Macafee (14 February, $p$ 442) in response to our article about the Liverpool urban obstetric flying squad.

All the correspondents referred to mixed urban and rural areas and outlying maternity units. We do not have such units in our solely urban practice, and our choice is therefore limited to transfer to the main unit or a domiciliary anaesthetic. We agree, however, that in remote areas the best solution would be to provide senior help (by which we mean that of consultants or senior registrars experienced in obstetric anaesthesia) to an outlying unit, where prior arrangements for emergencies have to be planned in the cold light of day. The prospect of domiciliary anaesthesia should be daunting to all anaesthetists. Equipment can be demonstrated and practised with, but it is impossible to devise any training that can prepare adequately for the circumstances in which anaesthesia has to be administered on the kitchen table.

Dr Browne's remark that he finds the term "occasional anaesthetist" puzzling seems difficult to understand as in his own area only 16 general anaesthetics have been administered over the past six years in outlying maternity units.

We all seem to agree that retained placenta remains the overriding reason for giving an anaes- thetic. In our opinion, however, the transfer of such patients, with the placenta in situ, to a maternity unit has not been shown conclusively to cause any increase in morbidity or mortality. Indeed, if patients can be transferred to a peripheral unit where epidural anaesthesia can be performed, as stated by Drs Roberts and Macafee, then the degree of urgency must be considered to be low.

We would repeat that inexperience among junior staff, alternative cover arrangements, and the mixture of urban and rural practice are all factors that must be taken into account when each area or department decides on the provision of an obstetric flying squad. We agree with Dr Callander that no blanket policy is correct but would maintain that in purely urban areas the anaesthetist's presence is now an unnecessary luxury.

Though we recognise that for geographical reasons there may be a few areas of the United Kingdom where small outlying units are the best provision possible, we wonder whether adequate anaesthetic cover, and presumably also skilled obstetric cover, can be provided by the obstetric flying squad.

Mill Road Maternity Hospital

G M KIDD Liverpool L6 2A

T RYAN

\section{Treating postural hypotension}

SIR,-Dr R D S Watson (14 February, p 390) correctly emphasises the use of physical methods as initial treatment for postural hypotension followed by fludrocortisone or a non-steroidal antiinflammatory drug. He omitted to mention, however, two other important treatments that have been discussed ${ }^{12}$ : the combination of fludrocortisone with a non-steroidal anti-inflammatory drug, which may be successful in postural hypotension refractory to other drugs, and atrial tachypacing, which has proved useful when other methods have failed.

Dr Watson warned of the dangers of hypertension with the use of sympathomimetics but did not mention that hypertension can be overcome by simultaneous use of a $\beta$ antagonist. ${ }^{12}$ In individual patients with postural hypotension several mechanisms may be at work to varying degrees, and it is important to tailor treatment to the individual requirements. Attention should thus also have been drawn to other drugs that may be successful in some cases of postural hypotension-namely, metoclopramide, yohimbine, propranolol, midodrine (a newer $\alpha$ antagonist), the combination of an $\alpha$ antagonist with fludrocortisone,$^{12}$ and the use of clonidine's partial $\alpha$ agonist activity. $^{3}$

Department of Geriatric Medicine,

I BLEDDYN DAVIES

Leicester General Hospital,

Leicester LE5 4PW

\section{Anonymous. $M$} 2 Davies IB. Chronic hypotension $7 R$ Soc Med 1982;75:577-80.

3 Bannister R. Treatment of progressive autonomic failure. In Bannister R, ed. Autonomic failure. A textbook of clinical disorders of the autonomic nervous system. Oxford: Oxford University Press, 1983:316-34.

AUTHOR's REPLY-Dr I B Davies's letter raises several important issues. Firstly, what is the function of a leading article? It is clearly impossible to review exhaustively in the space of 600 words all the forms of treatment, in various combinations, that have been used in patients with postural hypotension. My purpose was to describe, briefly for a general readership, the pathophysiology of this uncommon condition and the principles of treatment, emphasising some of the hazards, and to highlight some new treatments that may prove beneficial.

Secondly, we have a responsibility to ensure that there is a sound basis for any treatment that we recommend. I attempted to draw readers' attention to some of the important points-for example, few, if any, studies have investigated the benefit of drugs in addition to night time head up tilt. The combination of a non-steroidal anti-inflammatory drug with fludrocortisone may be beneficial, but in the paper cited in Dr Davies's review only two of the five patients studied showed sustained improvement. ${ }^{1}$ Atrial tachypacing has been reported to be helpful in a patient described by Moss et al, who presented very limited evidence to indicate that sympathetic failure was the underlying cause (the patient may have had sick sinus syndrome) Dr Davies cites two additional papers in his review to support the value of this treatment: one letter concerned interpretation of plasma catecholamine concentrations in the paper by Moss et al and did not discuss therapeutic effects ${ }^{3}$ and the other described a patient who failed to respond to this form of treatment. ${ }^{4}$ Dr Davies commended yohimbine, but the reference quoted concerned patients with postural hypotension caused by the antidepressant clomipramine rather than those with autonomic failure. ${ }^{5}$ Finally, Dr Davies refers to midodrine as a $\alpha$ antagonist; it is in fact an $\alpha$ agonist, which has been associated with supine hypertension. ${ }^{6}$

There is great potential for causing harmful side effects with drugs in patients with postural hypotension. I would maintain that recommendations should be based on carefully performed studies in which the patients and their responses to treatment are clearly documented.

R D S WATSON

Dudley Road Hospital

Birmingham B18 7QH

1 Watt SJ, Tooke JE, Perkins CM, Lee M. The treatment of idiopathic orthostatic hypotension: a combined fludrocortisone and flurbiprofen regime. Q 7 Med 1981;50:205-12.

Moss AJ, Glaser W, Topol E. Atrial tachypacing in the treatment of a patient with primary orthostatic hypotension. $N \mathrm{Engl} f$ Med 1980;302:1456-7.

3 Hiltbold P. Atrial tachypacing for primary orthostatic hypotension. N Engl f Med 1980;303:885.

4 Goldberg MR, Robertson RM, Robertson D. Atrial tachypacin for primary orthostatic hypotension. N Engl f Med 1980;303. $885-6$

5 Des Lauriers A. Esset favorable du chlorhydrate de yohimbin sur l'hypotension orthostatique induite par la clomipramine. Nouv Presse Med 1979;8:2838.

6 Schirger A, Sheps SG, Thomas JE, Fealey RD. Midodrine. A new agent in the management of idiopathic orthostatic hypoension and Shy-Drager syndrome. Mayo Clin Proc 1981;56: $429-33$

Macrocytic anaemia in patients treated with sulphasalazine for rheumatoid arthritis

SIR,-Dr M Greaves and colleagues ( 7 February, $p$ 373) suggest that folate deficiency with sulphasalazine treatment of rheumatoid arthritis is an uncommon complication; this is not our experience. Since our report, which suggested that this problem may be more common in patients with rheumatoid arthritis than inflammatory bowel disease, we have seen a further five cases of macrocytosis associated with low serum folate concentrations in patients with rheumatoid arthritis treated with sulphasalazine. None of these patients had other possible causes of folate deficiency.

We acknowledged in the report that some of the patients had other medical conditions, but we considered these to be non-contributory. The bacterial overgrowth (case 1) caused by jejunal 
diverticulae was thought unlikely to cause folate deficiency but may have contributed to the B12 deficiency. The coeliac disease (case 2) had been present for several years, was stable, and had not previously caused macrocytosis. The poor diet (case 3) was long standing and had not previously caused macrocytosis. A mild haemolysis does occur with sulphasalazine treatment (case 4).

We would emphasise that treatment with sulphasalazine has an experimentally proved mechanism for inducing folate deficiency, which is dose dependent. The paper by Grindulis and McConkey cited by Dr Greaves and coworkers concluded that "caution is therefore necessary if more than 2 grams of sulphasalazine daily is given in rheumatoid arthritis; in such circumstances clinical or haematological evidence of deficiency is more likely to develop because the mechanism by which the drug antagonises folate metabolism is dose dependent." All but one of our patients received a higher dose than this.

Peter Prouse DEIDRE SHAWE

J M GUMPEL

Northwick Park Hospital,

Middlesex HA1 3UJ

1 Grindulis KA, McConkey B. Does sulphasalazine cause folate deficiency in rheumatoid arthritis? Scan $\mathcal{f}$ Rheumatol 1985;14:265-70.

\section{Social future of elderly admitted to acute care hospital}

SIR,-In the study by Dr Françoise RoudotThoraval and colleagues ( 7 March, p 608) 32 of the 39 patients discharged to long term care had a negative view of it at the start of their acute admission, and no patient who was free of family pressure wanted to be transferred to long term care. The factor that predicted whether a patient would go into long term care was the view of the family, not that of the patient.

Secondly, though it is difficult to find a comparable British series, a transfer rate from acute to long term care of $31 \%$ seems very high. Might this high transfer rate itself be responsible for the strong correlation between being transferred to a long term bed and staying longer in the acute one? Perhaps the local long stay sector is unable to cope with this transfer rate and the system is dealing with the overload by allowing a backup of patients in the acute sector.

I have not seen the cited papers by Kane et al but presume that they report American experience. As to the importance of the age and mental state of the patient, several British studies have shown them to be valuable in predicting the outcome of hospital admissions. ${ }^{1-3}$

In this unit we emphasise the need for very early involvement of the family in an old person's care. In the difficult balance between taking risks and preserving independence, however, we believe that British families tend to opt for safety at the expense of freedom. We would therefore advise against any movement to give families the predominant voice in determining placement. It would also be unwise to ignore the financial consequences of non-essential use of long term facilities.

C REISNER

Department of Geriatric Medicine,

London Hospital,

1 Hodkinson HM, Hodkinson I. Death and discharge from a geriatric department. Age Ageing 1980;9:220-8.

2 Farrow SC, Rablin MR, Silver CP. Geriatric admissions in east London 1962-72. Age Ageing 1976;5:49-55.

3 Isaacs B. Prognostic factors in elderly patients in a geriatric institution. Gerontologia Clinica 1965;7:215.
What contribution has cardiac surgery made to the decline in mortality from coronary heart disease?

SIR,-As Drs John M Neutze and Harvey D White point out (14 February, p 405), a major problem in assessing the contribution of cardiac surgery to the decline in coronary heart disease mortality is in estimating the potential mortality of the surgical patients had they not had surgery. The earlier, and much lower, estimates are a result of different assessments of the likely benefit of surgery. Drs Goldman and Cook ${ }^{1}$ and $\mathrm{I}^{2}$ prefer an estimate based on a randomised clinical trial, with all its limitations. Drs Neutze and White prefer estimates based on a variety of case series from North America (which I used in estimating an upper limit of benefit). It seems, however, that because of the lack of appropriate data from Auckland on the survival of a comparable group of medically treated patients Drs Neutze and White are guilty of the same "conceptual fallacy" as previous investigators

It might be useful to take a broader look at the potential impact of cardiac surgery. In New Zealand coronary heart disease mortality has declined in all age, sex, and race groups. In general, however, coronary surgery has been restricted to people under 70 years of age. Moreover, the decline in mortality began well before coronary artery bypass surgery was introduced in New Zealand. To suggest that surgery alone was responsible for a major part of the decline (26-42\%) requires a complex explanation of the overall decline as other factors must therefore be operating in the population subgroups not exposed to surgery.

Another explanation would be that the major factors in the decline must be those to which the whole population is exposed. Evidence from New Zealand shows, in fact, that dietary changes and, to a lesser extent, a reduction in tobacco consumption are likely to be the major factors in the decline in coronary heart disease mortality. ${ }^{3}$

University of Auckland,

ROBERT BEAGLEHOLE

New Zealand

1 Goldman L, Cook EF. The decline in ischemic heart disease mortality rates: an analysis of the comparative effects of medical interventions and changes in lifestyle. Ann Intern Med 1984;101:825-36.

2 Beaglehole R. Medical management and the decline in mortality from coronary heart disease. $\mathrm{Br} M e d \mathcal{f}$ 1986;292:33-5.

3 Jackson RT, Beaglehole R. Dietary fat, serum cholesterol, cigarette smoking and the decline in coronary heart disease mortality in New Zealand. Int $\mathcal{J}$ Epidemiol (in press).

\section{Eczema herpeticum: a potentially fatal} disease

SIR,-As Dr I $R$ Sanderson and colleagues (14 March, p 693) rightly point out, eczema herpeticum - and eczema vaccinatum before smallpox vaccination was stopped-is a potentially fatal disease. During 1950-5, 16 cases of eczema herpeticum were seen at the Hospital for Sick Children, Great Ormond Street. ${ }^{1}$ Of these, 11 were considered to be severe, with fever lasting more than 12 days. In September 1953 an outbreak of eczema herpeticum occurred in the skin ward of the hospital. Six severe cases developed, and in one of these the patient died on the tenth day of the illness. ${ }^{2}$ The outbreak probably occurred because of incorrect diagnosis in the first case, ${ }^{23}$ and herpes virus infection was spread by two nurses who had cutaneous vesicular lesions on the hands. All cases of herpes infection were confirmed by virus isolation. In the patient who died diffuse necrotic lesions were found in the adrenals and also in the liver and lungs. ${ }^{2}$ The presence of herpetic type inclusion bodies and isolation of virus from these organs indicated that herpes virus was responsible for these typical and atypical necrotic lesions. In two subsequent fatal cases necrotic lesions were found confined to the adrenals.

One of the patients affected by the ward outbreak subsequently suffered four separate attacks of eczema herpeticum with thrombocytopenia and died at the age of 4 years with diffuse eczema herpeticum, chronic interstitial pneumonitis, and advanced glomerulonephritis, complicated by an overwhelming infection with Pseudomonas pyocyanea. $^{3}$ Some years later, when this case was reviewed, it was realised that this patient was probably suffering from the Wiskott-Aldrich syndrome.

I agree with Dr Sanderson and colleagues that early identification and treatment may be life saving, as is recognition of the mode of spread. Unfortunately, when these cases were seen modern methods of treatment of eczema were not then available.

J A DUDGEON

Ashford,

Kent TN25 7AZ

1 Jackson ADM, Dudgeon JA. Kaposi's varicelliform eruption: diagnosis and treatment. Great Ormond Street foumal 1951;1:125-32.

2 Rugh RCB, Dudgeon JA, Bodian M. Kaposi's varicelliform eruption (eczema herpeticum) with typical and atypical visceral lesions. Foumal of Pathology and Bacteriology 1955;69:67-80.

3 Institute of Child Health. A case of recurrent Kaposi's varicelliform eruption. Br Med $\mathcal{J}$ 1962;i:313-20.

\section{Outbreak of Weil's disease in a food fad} commune in India

SIR,-In response to the queries made by Dr Singh (14 February, p 443), we would like to reiterate that in our report the patient in the index case, which alerted us to the fact that rat meat was the source of infection, did not belong to the Mussher commune and did not participate in the catching, handling, or cooking of the rats.

Musshers are basically wandering communes and are considered to be untouchable. A few such communes, however, have undergone sociocultural changes. After independence considerable efforts were made to bring about agricultural reform, and some landowners started to employ members of Mussher communes as agricultural workers and allowed them to settle permanently outside the main village. Nevertheless, they are still at the mercy of the landowners, and because they are considered to be untouchable they have never been allowed to live inside the villages.

One group of the tribe still wanders from one village to another, its members earning their living by performing various plays and tricks.

As we stated in our article, the rats were grilled hastily over a makeshift bonfire, without the use of cooking utensils or the addition of salt during cooking. Salt was smeared on the meat only at the time of consumption, and it is therefore highly unlikely that salt destroyed leptospira, especially at the centre of the rat meat. Dr Singh should also be aware of the fact that in most of rural India the villagers believe that the sprinkling of salt over fire invites a catastrophe like leprosy.

It is true that leptospires usually fail to survive in gastric acid, but they can easily enter abraded skin or mucosa. ${ }^{1}$ In the index case the leptospires in the contaminated food may have entered through the upper gastrointestinal mucosa or escaped destruction by gastric hydrochloric acid.

Though some of the Musshers' habits might 